\title{
Comparison of Land-Cover Classification Methods in the Brazilian Amazon Basin
}

\author{
Dengsheng Lu, Paul Mausel, Mateus Batistella, and Emilio Moran
}

\begin{abstract}
Four distinctly different classifiers were used to analyze multispectral data. Which of these classifiers is most suitable for a specific study area is not always clear. This paper provides a comparison of minimum-distance classifier (MDC), maximumlikelihood classifier (MLC), extraction and classification of homogeneous objects (ECHO), and decision-tree classifier based on linear spectral mixture analysis (DTC-LSMA). Each of the classifiers used both Landsat Thematic Mapper data and identical field-based training sample datasets in a western Brazilian Amazon study area. Seven land-cover classesmature forest, advanced secondary succession, initial secondary succession, pasture lands, agricultural lands, bare lands, and water-were classified. Classification results indicate that the DTC-LSMA and ECHO classifiers were more accurate than were the MDC and MLC. The overall accuracy of the DTCLSMA approach was 86 percent with a 0.82 kappa coefficient and ECHO had an accuracy of 83 percent with a 0.79 kappa coefficient. The accuracy of the other classifiers ranged from 77 to 80 percent with kappa coefficients from 0.72 to 0.75 .
\end{abstract}

\section{Introduction}

Monitoring the Brazilian Amazonia land cover has had a great deal of attention during the past decades. The colonization of vast areas associated with the advance of agriculture, cattle ranching, logging operations, infrastructure construction, and urbanization has produced processes of land-cover change such as deforestation and forest regeneration that are not always easily captured through the use of Landsat Thematic Mapper (TM) data. Despite these difficulties, Landsat data are still very suitable for detecting the processes mentioned with enough detail to provide valuable information to agencies if the most appropriate classification schemes and classifiers are used. Using higher spatial resolution data, such as Ikonos, for

\section{Lu is with the Center for the Study of Institutions, Population, and Environmental Change (CIPEC), Indiana University, 408 N. Indiana Ave., Bloomington, IN 47408 (dlu@indiana.edu).}

P. Mausel is with the Department of Geography, Geology, and Anthropology, Indiana State University, Terre Haute, IN 47809 (pmausel@hotmail.com).

M. Batistella is with the Brazilian Agricultural Research Corporation, EMBRAPA Satellite Monitoring, Campinas, São Paulo, Brazil (mb@cnpm.embrapa.br).

E. Moran is with the Center for the Study of Institutions, Population, and Environmental Change (CIPEC), and the Anthropological Center for Training and Research on Global Environmental Change (ACT), Indiana University, $408 \mathrm{~N}$. Indiana Ave., Bloomington, IN 47408 (moran@indiana.edu). large areas would be a virtually impossible task considering the current state-of-the-art of regional land-cover classification. Many classifiers have been developed, but it is difficult to identify the most appropriate approach to use for features of interest in a given study area. Different results can be attained depending on the classifiers used. In this paper, four approaches-minimum-distance classifier (MDC), maximumlikelihood classifier (MLC), extraction and classification of homogeneous objects (ECHO), and decision-tree classifier based on linear spectral mixture analysis (DTC-LSMA)—were implemented to classify Landsat TM data in a western Brazilian Amazon study area in Rondônia using identical training samples and test data sets. Seven land-cover classes were classified: mature forest, advanced secondary succession (SS2), initial secondary succession (SS1), pasture lands, agricultural lands, bare lands, and water. Overall accuracy and kappa analysis were determined for each classification approach and results compared among the classifiers. The purpose of this paper is to contribute to a better understanding of the potential of using different classifiers to develop important land cover information for the Brazilian Amazon basin using Landsat TM data.

\section{Amazonian Land-Cover Classification}

The Brazilian Amazon basin contains the largest continuous rain forest in the world. Since the 1970s, deforestation in this region has gradually increased from $152,200 \mathrm{~km}^{2}$ in 1978 to $587,727 \mathrm{~km}^{2}$ in 2000 (INPE, 2002). Collectively, 30 to 50 percent of the deforested area in the Amazon region is in some stage of secondary succession. The increasing role of successional forests in global carbon budget and functional aspects within Amazonian ecosystems and landscapes affecting soil fertility, vegetation structure and composition, and faunal dispersion requires accurate information regarding subclasses of successional stages (Moran et al., 1994; Brondízio et al., 1996; Lu et al., 2003b). For example, accurate estimation of rates of carbon changes following deforestation or interrupted secondary succession (e.g., converting intermediate succession to pasture or crop renewing a succession cycle) requires successional stage information that can be associated with biomass. Knowledge of relationships between stages of succession with their structural characteristics and parameters associated with soils, topography, surface hydrology, microclimates, landcover spatial patterns, land-use history, and other cultural/ political/economic influences requires knowledge of the

Photogrammetric Engineering \& Remote Sensing Vol. 70, No. 6, June 2004, pp. 723-731.

0099-1112/04/7006-0723/\$3.00/0 (C) 2004 American Society for Photogrammetry and Remote Sensing 
distribution of succession subclasses viewed within a multitemporal context. Modeling of succession rates and of succession stand characteristics (i.e., biomass and vegetation structure) is needed to make land-use/land-tenure/landmanagement decisions that promote economic development of the Amazon Basin while still retaining a reasonable and sustainable level of environmental integrity. This requires the availability of accurate, comparable, and Basin-wide multiclass succession feature distributions, both current and historic.

Because of the importance of distinguishing subclasses of successional stands, scientists from Indiana State University, Indiana University, and Embrapa Satellite Monitoring have been engaged in developing accurate classifications in multiple Amazonian sites since the early 1990s. Mausel et al. (1993) analyzed Landsat TM spectral responses with different successional stages and concluded that TM data can be used successfully to identify three successional stages if supported by abundant and detailed field survey data. Similar studies were conducted by Li et al. (1994), Moran et al. (1994), and Brondízio et al. (1996). They found that extraction and classification of homogeneous objects (ECHO) was a good classifier for distinguishing between different successional stages and mature forest. However, the classification results greatly depended on the quality of training datasets and required abundant and accurate field measurements from all classes of interest. One of the key steps for successful classification is to select high quality secondary succession plots as training sample datasets. Confusion often occurs in identifying different successional stages or distinguishing between advanced secondary succession and mature forest ( $\mathrm{Lu}$ et al., 2003a; $\mathrm{Lu}$ et al., 2003b), because remotely sensed data primarily capture canopy information. The canopy structures between advanced secondary succession and mature forest can be very similar, although these stands have different ages, species composition, and biomass. The smooth transition between different successional stages also causes problems for image classification.

Many efforts have been made to classify successional stages in the Amazon basin, but accurate classification is still difficult and time-consuming. The heterogeneity in vegetation structure is a major problem in classification, as is the limitation of spatial resolution, i.e., where a single Landsat TM pixel often contains more than one land-cover class. Even within the same vegetation class, there is often great variation in plant species, plant geometry, vegetation structure, and biomass. For example, the initial succession is often confused with degraded pasture. Coffee plantations and agroforestry are often confused with successional stages. The confusion between land-cover classes makes digital classification difficult using traditional approaches, such as MLC (Mausel et al., 1993; Batistella, 2001; Lu, 2001). In order to avoid these problems, much previous research focused on Amazonian land-cover classification or change detection did not include subclasses of succession (Lucas et al., 1993; Adams et al., 1995; Rignot et al., 1997; Roberts et al., 1998a; Lucas et al., 2002). However, different stages of secondary succession have played an important role in Amazonia. Hence, classification of successional stages becomes of considerable significance. Different classifiers have their own advantages and disadvantages. Selecting a classifier most suitable for the characteristics of the study area can improve classification results.

\section{Brief Description of Classifiers Used in This Research}

Land-cover classification accuracy is a major concern in remote sensing applications. In order to improve classification accuracy, scientists have made great efforts to develop advanced classification algorithms, such as the Extraction and Classification of Homogeneous Objects (ECHO) classifier (Kettig and Landgrebe, 1976; Landgrebe, 1980), neural network
(Foody et al., 1995; Paola and Schowengerdt, 1997), fuzzy set classification (Foody, 1996; Mannan et al., 1998), subpixel classifier (Huguenin et al., 1997), and per-field classification (Pedley and Curran, 1991; Aplin et al., 1999). Moreover, the classification results are also influenced by a variety of factors, including availability of remotely sensed data, landscape complexity, image band selection, the classification algorithm used, analyst's knowledge about the study area, and analyst's experience with the classifiers used. For a given study area, selecting a suitable classifier becomes significant in improving the classification results. A comparative study of different classifiers is necessary to understand which classifier is most suitable for a specific landscape. Hence, four classifiers, ranging from simple MDC to complex DTC-LSMA, are analyzed in this paper. Of the many classifiers, MDC and MLC may be the most popular due to their simple theory and availability in almost any image processing or GIS software packages. In contrast, the ECHO and DTC-LSMA classifiers are relatively new or less commonly used, and consequently they are not found in many remote sensing textbooks or software packages.

\section{MDC and MLC}

MDC is a non-parametric classifier that has no assumption of data sets for features of interest. It is computationally simple and fast, only requiring the mean vectors for each band from the training data. Candidate pixels are assigned to the class that is spectrally closer to the sample mean. This method does not consider class variability; thus, large differences in the variance of the classes often lead to misclassification.

MLC is a parametric classifier that assumes normal or near normal spectral distribution for each feature of interest. An equal prior probability among the classes is also assumed. This classifier is based on the probability that a pixel belongs to a particular class. It takes the variability of classes into account by using the covariance matrix; thus, it requires more computation per pixel than does the MDC. Training samples insufficient in number or non-representative of features of interest or having multimode distributions often lead to poor classification results. MLC requires sufficient representative spectral training sample data for each class to accurately estimate the mean vector and covariance matrix needed by the classification algorithm. When the training samples are limited or non-representative, then inaccurate estimation of the mean vector and covariance matrix often results in poor classification results. In this situation, MDC is possibly more suitable to use when few training samples are used because the estimation of covariance matrix is not required (Jensen, 1996). A detailed description of MDC and MLC can be found in many textbooks (Jensen, 1996; Richards and Jia, 1999; Lillesand and Kiefer, 2000).

\section{ECHO}

The ECHO classifier is part of the MultiSpec software package that has been developed at Purdue University and funded by NASA (Kettig and Landgrebe, 1976; Landgrebe, 1980; Biehl and Landgrebe, 2002). ECHO is a multistage spectral-spatial classifier that combines spectral and spatial/textural features; hence, it is hybrid in character. Four stages are involved during the classification: (1) an analyst defines partitions within the feature space ( 2 by 2,3 by 3,4 by 4 , etc.) that creates multipixel cells; (2) an analyst sets thresholds to determine the homogeneity of pixels within each cell. After processing, each cell is then either considered a single multipixel entity where individual pixel spectral statistics are merged or they function as individual pixels just located within a cell's coordinates; (3) full cells and individual pixels within some cells are aggregated based on spectral statistical associations between them; and (4) the aggregations of cells of pixels and single pixels are processed by an MLC to provide the final results. 
Research has indicated that incorporation of textural or spatial or object-oriented data enhances the information content of per-pixel spectral data in many applications (Alonso and Soria, 1991; Arai, 1993; Kartikeyan et al., 1994). ЕСHO includes spatial/contextual data into remote sensing classifications and has proven to be successful in several tropical forest applications in Brazil. ECHO accurately delineated three classes of secondary succession using Landsat TM data supported by very detailed field-measured data near Altamira, Brazil (Mausel et al., 1993; Moran et al., 1994). An application of ECHO in Marajo Island in the Amazon Estuary area had similar successful results in differentiating three secondary succession stages as well as many other flood-plain forest features (Brondízio et al., 1996). Several different research projects in various parts of the Amazon have had success using ECHO. In every instance, detailed ground-truth data were available to support the ECHO classification.

In unpublished research, one of the authors of this article (P. Mausel) used ECHO extensively in classifying typical crops of the Midwestern U.S. (corn, soybeans, and wheat). Classification accuracy using ECHO in this context was no better than using more standard classifiers such as MLC. It is hypothesized that ECHO does best where classes of interest are mixed with high variance that typically causes per-pixel classifiers to have great difficulty in feature discrimination. ECHO simplifies complex mixtures of pixels and often can extract the essence of a mass of seemingly complex spectral responses. ECHO showed better results than other per-pixel classifiers in study areas with complex landscapes.

\section{DTC-LSMA}

LSMA assumes that the spectrum measured by a sensor is a linear combination of the spectra of all components within the pixel (Adams et al., 1995; Roberts et al., 1998a). It supports repeatable and accurate extraction of quantitative sub-pixel information (Smith et al., 1990), with fractions of the endmembers representing the areal proportions within the pixel. The LSMA approach has been used for many applications, including land-use/land-cover classification (Ustin et al., 1996; Cochrane and Souza, 1998; Aguiar et al., 1999; Theseira et al., 2002). The mathematic model can be expressed as

$$
R_{i}=\sum_{k=1}^{n} f_{k} R_{i k}+\varepsilon_{i}
$$

where $i(i=1, \ldots, m)$ is the number of spectral bands used; $k$ $=1, \ldots, n$ (number of endmembers); $R_{i}$ is the spectral reflectance of band $i$ of a pixel, which contains one or more endmembers; $f_{k}$ is the proportion of endmember $k$ within the pixel; $R_{i k}$ is known as the spectral reflectance of endmember $k$ within the pixel on band $i$; and $\varepsilon_{i}$ is the error for band $i$. A detailed description of LSMA can be found in Mustard and Sunshine (1999).

Endmember selection is the most important step in LSMA. It involves determination of the number of endmembers and the methods to select these endmembers. Ustin et al. (1996) indicates that, regardless of the number of bands, only two to six endmembers are needed to characterize the overall variance in the image to the noise level. Roberts et al. (1998b) found that two endmembers can model the majority of the image scene. Three endmembers (e.g., green vegetation or GV, shade, and soil) and four endmembers (e.g., GV, shade, soil, and non-photosynthetic vegetation or NPV) are often used (Smith et al., 1990; Adams et al., 1995; Shimabukuro and Smith, 1995; Cochrane and Souza, 1998; Aguiar et al., 1999; Small, 2001).

A variety of methods have been used to identify endmembers (Smith et al., 1990; Adams et al., 1993; Settle and Drake, 1993; Boardman et al., 1995; Bateson and Curtiss, 1996; Tompkins et al., 1997). In general, two categories of endmembers can be grouped: image endmembers and reference endmembers. Image endmembers are derived directly from the image itself and reference endmembers are derived from field measurements or laboratory spectra of known materials (Roberts et al., 1998a). For many remote sensing applications of LSMA, the image-based selection of endmembers is often used because they are easily obtained and represent spectra measured at the same scale as the image data (Roberts et al., 1998a). The endmembers are regarded as the extremes of the triangles of an image scattergram. Thus, the image endmembers can be derived from the extremes of the image feature space, assuming they represent the purest pixels in the images (Mustard and Sunshine, 1999). During the selection of endmembers, recognition of true endmembers from the outliers in the image is a key step for a successful LSMA application. Moreover, selection of endmembers is often an iterative process.

The least-squares solution is the most often used method in solving the linear mixture model (Smith et al., 1990; Shimabukuro and Smith, 1991; Garcia-Haro et al., 1996) due to its simplicity and ease of implementation. Two methods, i.e., constrained (Garcia-Haro et al., 1996; Aguiar et al., 1999) and unconstrained (van der Meer and de Jong, 2000) solutions are often used to unmix the linear mixture model. For a constrained unmixing solution, $f_{k}$ is subject to the following restrictions:

$$
\sum_{k=1}^{n} f_{k}=1 \quad \text { and } \quad 0 \leq f_{k} \leq 1 .
$$

For the unconstrained solution, the fraction $f_{k}$ may assume negative values and is not constrained to sum to one. However, the results from the unconstrained solution do not reflect the true abundance fractions of endmembers. The rootmean-square error (RMSE) was used to assess the fit of the model. It can be expressed as

$$
\text { RMSE }=\sqrt{\left(\sum_{i=1}^{m} \varepsilon_{i}^{2}\right) / m} .
$$

The RMSE is calculated for all image pixels. The larger the RMSE, the worse the fit of the model (Mather, 1999). So, the error image can be used to assess whether the endmembers are properly selected and whether the number of selected endmembers is sufficient.

After developing fraction images, a decision-tree classifier is frequently used to classify fraction images into different land-cover types (Roberts et al., 1998a; Rashed et al., 2001; Rogan et al., 2002). The decision-tree algorithm is a hierarchical classifier that compares the data with a range of properly selected features (Friedl and Brodley, 1997). Features are selected based on assessment of spectral distributions or separability of the classes with reference to ground-truth data. Currently, there is no generally established procedure for the selection; therefore, an expert must design each decision tree or set of rules. If a decision tree provides only two outcomes at each stage, the classifier is called a binary decision-tree classifier. The major advantages of the decision-tree classifier are that less computing time compared to MLC is needed and there is no need for calculating statistical errors. However, the accuracy depends fully on the design of the decision tree and the selected features. A detailed description about the selection of features in the decision-tree classification can be found in $\mathrm{Lu}$ et al. (2003b).

\section{Method}

\section{Description of the Study Area}

The state of Rondônia has experienced high deforestation rates over the last two decades. The deforestation rates in Rondônia ranged from 1.14 to 2.62 percent per year between 1991 and 


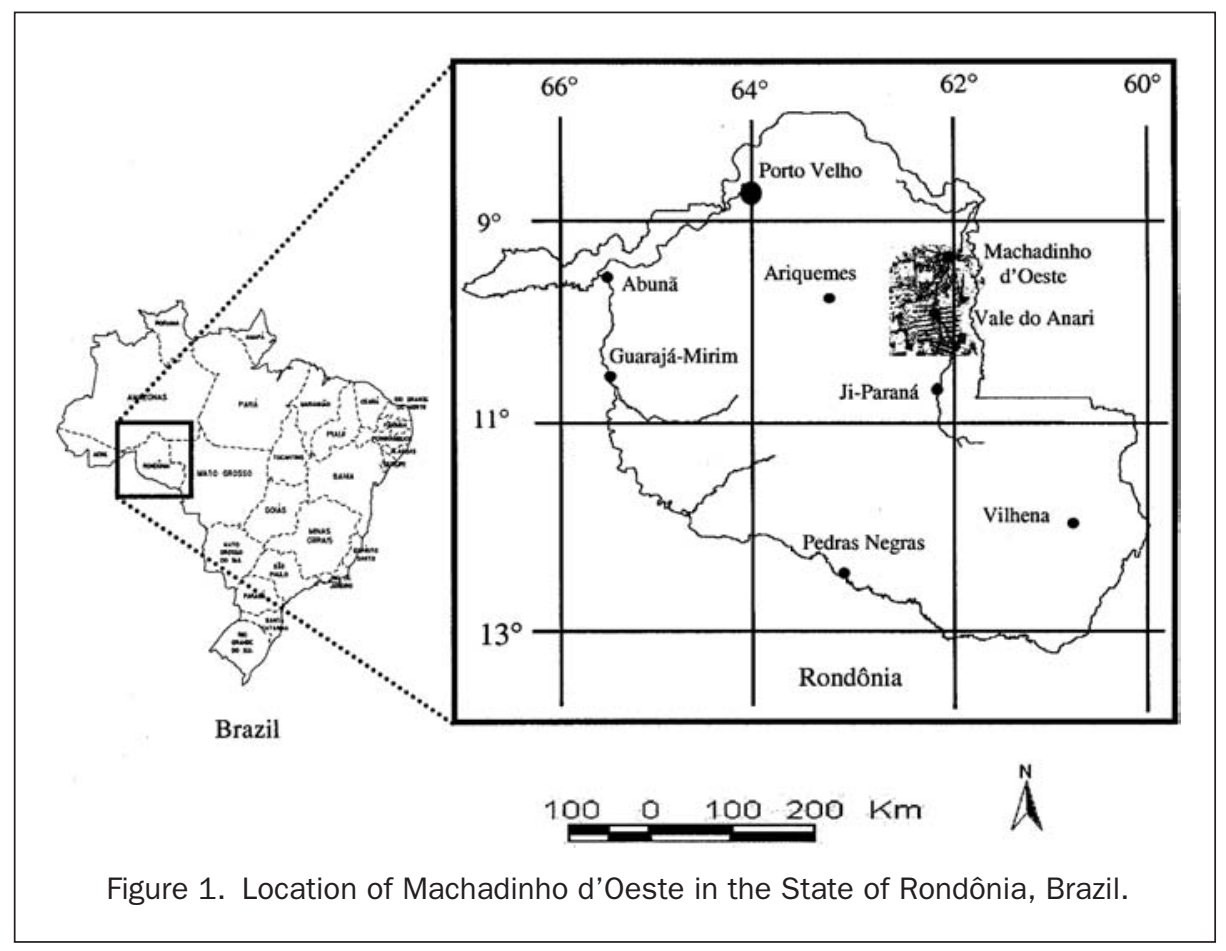

2000, much higher than the overall deforestation rate (ranging from 0.37 to 0.80 percent per year) in the Brazilian Amazon during the same period (INPE, 2002). Following the national strategy of regional occupation and development, colonization projects initiated by the Brazilian government in the 1970s played a major role in this process (Moran, 1981; Schmink and Wood, 1992). Most colonization projects in the state were designed to settle landless migrants. The immigrants have transformed the forested landscape into a patchwork of cultivated crops, pastures, and a vast area of fallow land.

The study area is located at Machadinho, northeastern Rondônia (Figure 1). The settlement of Machadinho covers about $2,000 \mathrm{~km}^{2}$ and is part of its respective municipality. Machadinho is adjacent to the borders with the states of Amazonas and Mato Grosso, which may offer potentials and constraints for future conservation and development. The size of the study area is approximately $1,120 \mathrm{~km}^{2}$ ( 35 by $32 \mathrm{~km}$ ). Settlement began in mid-1980s and major deforestation occurred in the late 1980s. The climate in this study area is classified as equatorial hot and humid, with a tropical transition area. A well-defined dry season lasts from June to August, and the annual average precipitation is $2,016 \mathrm{~mm}$ (Rondônia, 1998). The annual average temperature is $25.5^{\circ} \mathrm{C}$, and the monthly average humidity ranges from 80 to 85 percent. The terrain is undulating, ranging from 100 to $450 \mathrm{~m}$ above sea level. Several soil types have been identified, mainly alfisols, oxisols, ultisols, alluvial soils, and other less spatially represented associations (Bognola and Soares, 1999). Settlers, rubber tappers, and loggers inhabit the area, transforming the landscape through their economic activities and use of resources (Batistella, 2001). Farming systems are mainly household-based, and little depends on group efforts. Rubber tappers have rights over communal forest reserves where they practice extraction. Loggers play a major role in providing access to remote areas within the settlement as they open trails through the forest to reach valuable species.

Field Data Collection

Fieldwork was conducted during the dry seasons of 1999 and 2000. The procedure used for surveying vegetation was a multilevel technique adapted from methods used by the Center for the Study of Institutions, Population, and Environmental Change (CIPEC, 1998) at Indiana University. Preliminary image classification and band-composite printouts indicated candidate areas to be surveyed, and a flight over the areas provided visual insights about the size, condition, and accessibility of each site. The surveys were carried out in areas with relatively homogeneous ecological conditions (e.g., topography, distance from water, and land use) and uniform physiognomic characteristics. After defining the area to be surveyed (plot sample), three subplots $\left(1 \mathrm{~m}^{2}, 9 \mathrm{~m}^{2}\right.$, and $\left.100 \mathrm{~m}^{2}\right)$ were randomly selected to accurately represent the variability within the plot sample (Figure 2). The center of each subplot was randomly selected. Seedlings were defined as young trees or shrubs with a stem diameter smaller than $2 \mathrm{~cm}$. Saplings were defined as young trees with a stem diameter at breast height (DBH) greater than $2 \mathrm{~cm}$ and smaller than $10 \mathrm{~cm}$. Trees were defined as woody plants with a DBH greater than or equal to $10 \mathrm{~cm}$. Total tree height, stem height (the height of the first main branch), and DBH were measured for all trees in the $100-\mathrm{m}^{2}$ area. Height and DBH were measured for all saplings in the $9-\mathrm{m}^{2}$ area. Ground cover estimation and counting of individuals were carried out for seedlings and herbaceous vegetation in the $1-\mathrm{m}^{2}$ area. During fieldwork, stand parameters such as total tree height and DBH in 26 plots covering secondary succession and 14 plots covering mature forest were measured. Meanwhile, more secondary succession and mature forest plots, and hundreds of other land-cover observations (such as degraded pasture, cultivated pasture, coffee plantation, crops, bare lands, etc.) were identified during the fieldwork. A detailed description of field-data collection methods and the statistical description of vegetation inventory data are provided in Batistella (2001) and Lu et al. (2003a).

\section{Image Preprocessing}

Accurate geometric rectification and atmospheric calibration are two important aspects in image preprocessing. In this research, Landsat 5 TM data acquired on 18 June 1998 were geometrically rectified using control points taken from 


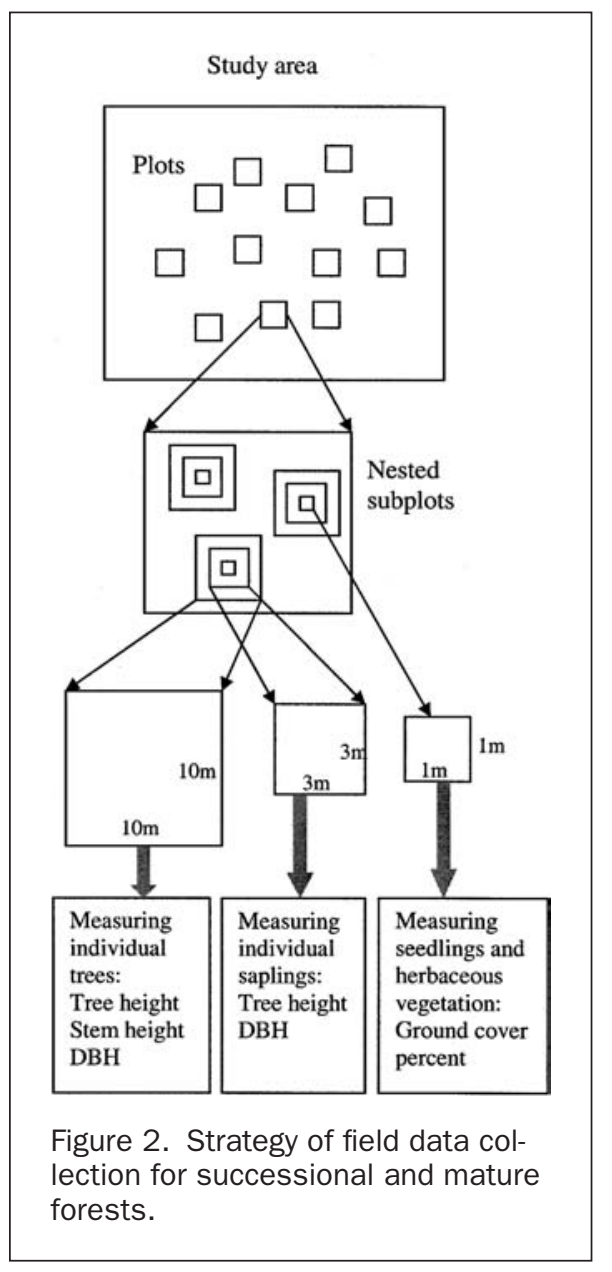

topographic maps at 1:100,000 scale (Universal Transverse Mercator or UTM south 20 zone). A nearest-neighbor resampling technique was used and a root-mean-square error of less than 0.5 pixel was obtained. An improved image-based dark object subtraction (DOS) model was used to implement radiometric and atmospheric correction (Chavez, 1996; Lu et al., 2002). The gain and offset for each band and the sun elevation angle were obtained from the image header file. The path radiance was identified based on clear water for each band. The atmospheric transmittance values for visible and near-infrared bands were derived from Chavez (1996), which were an average for each spectral band derived from the radiative transfer code. For middle infrared bands, the atmospheric transmittance was set to one. The surface reflectance values after calibration fall within the range between 0 and 1 . For the convenience of data analysis, the reflectance values were rescaled to the range between 0 and 100 by multiplying by 100 for each pixel.

\section{Determination of the Land-Cover Classification Scheme}

The selection of the land-cover classification scheme was motivated by two factors: (1) our previous experience in landcover classification in the Amazon basin during the past ten years and (2) the requirement of subclasses of secondary succession for Amazonian research. The classes selected must be suitable to assess the human dimensions of landscape change in the Amazon basin. The study of succession is a major key to understanding human-physical relationships. Changes in vegetation stand structures through secondary succession can directly be modeled into biomass changes, which in turn can be modeled into $\mathrm{CO}_{2}$ gas versus sequestered $\mathrm{C}$ data that is the core of global warming/global atmospheric changes. Our pre- vious research focusing on Amazon land-cover classification has shown that up to three successional stages can be classified using TM data (Mausel et al., 1993; Li et al., 1994; Moran et al., 1994, Brondizio et al., 1996). But in this study area, the majority of successional stages are less than ten years old on the 1998 TM image. According to our research in this area, two stages (i.e., SS1 and SS2) can be represented and detected using Landsat data (Batistella, 2001; Lu et al., 2003a). As an initial step, a total of 11 classes-mature forest, SS2, SS1, agroforestry, degraded pasture, cultivated pasture, coffee, crops, bare lands, urban, and water-were selected. The areas with grass cover greater than 75 percent were defined as cultivated pasture, and with grass cover between 25 and 75 percent and used as pasture were assigned as degraded pasture. Successional forests were assigned solely to the areas where the grass cover was less than 25 percent, which generally occurs in sites that have been abandoned for more than two years. Then the successional forests were divided into SS1 and SS2 based on the vegetation stand structure, such as ratio of tree biomass to total biomass, average stand DBH, and average stand height. A detailed method for secondary succession classification based on stand structure can be found in Lu et al. (2003a). Considering the confusion of some classes, seven classes were merged in the final result: mature forest, advanced secondary succession (SS2), initial secondary succession (SS1), pasture (degraded and cultivated pastures), agricultural lands (including coffee plantation, agroforestry, and annual crops), bare lands (including urban, road, and some bare soils), and water.

\section{Land-Cover Classification}

A total of 172 plots, covering 11 classes, were selected as training sample datasets. A range of 12 to 20 plots for each class was used. MDC, MLC, and ECHO were conducted using these training sample plots based on six TM bands. DTC-LSMA was conducted based on three fraction images developed using LSMA. After a preliminary classification, the 11 classes were merged into seven classes to assess final results. A majority filter with a 3-by 3 -window size was used to remove the "salt and pepper" on the classified images.

Before implementing the DTC-LSMA, it was necessary to reduce the correlation between some TM bands. A standardized principal component analysis (SPCA) was used to transform the atmospherically calibrated TM images into six principal components (PC). The last two PCs were discarded due to their very low variance and limited information content. Hence, the first four PCs were used in the LSMA to convert the image data into physically based fraction images.

Endmembers were initially identified from the TM image based on ground-truth data. The shade endmember was identified from the areas of clear and deep water and the GV endmember was selected from the areas of dense pasture. Soil endmembers were selected from road intersections and from bare soils in agricultural lands. These initial endmembers were compared with those endmembers selected from the scatterplot of PC1 and PC2 and scatterplot of PC1 and PC3. The endmembers whose curves were similar but located at the extreme vertices of the scatterplot were finally selected. An average of 30 to 50 pixels of these vertices was calculated. Then, an unconstrained least-squares solution was used to unmix the first four PCs into three endmember fraction images. Because the fractions represent the biophysical characteristics, different vegetation stand structures and land-cover types have their own proportion compositions. A decision tree was used to classify the fraction images based on thresholds for each class derived from the same training sample data.

\section{Accuracy Assessment}

A common method for classification accuracy assessment is through the use of an error matrix. Literature has provided the meanings and calculation methods for overall accuracy (OA), 
table 1. Comparison of Classification Percent Accuracy among Different Classifiers

\begin{tabular}{|c|c|c|c|c|c|c|c|c|}
\hline \multirow{3}{*}{$\begin{array}{l}\text { Land-Cover } \\
\text { Types }\end{array}$} & \multicolumn{8}{|c|}{ Algorithm Types } \\
\hline & \multicolumn{2}{|c|}{ MDC } & \multicolumn{2}{|c|}{ MLC } & \multicolumn{2}{|c|}{ ECHO } & \multicolumn{2}{|c|}{ DTC-LSMA } \\
\hline & UA & PA & UA & $\mathrm{PA}$ & UA & $\mathrm{PA}$ & UA & $\mathrm{PA}$ \\
\hline Forest & 94.33 & 98.71 & 93.65 & 98.71 & 94.71 & 99.47 & 95.73 & 98.77 \\
\hline SS2 & 29.30 & 59.35 & 31.37 & 58.39 & 28.26 & 48.79 & 35.02 & 62.58 \\
\hline SS1 & 74.04 & 67.74 & 84.98 & 69.31 & 92.87 & 58.16 & 91.43 & 70.95 \\
\hline Pasture & 85.25 & 58.98 & 86.95 & 65.83 & 83.97 & 87.96 & 84.96 & 89.02 \\
\hline Agriculture & 80.53 & 80.66 & 72.17 & 83.14 & 75.33 & 82.03 & 87.71 & 84.96 \\
\hline Bare land & 60.98 & 93.77 & 65.96 & 97.66 & 85.75 & 100.00 & 98.22 & 86.68 \\
\hline Water & 100.00 & 87.17 & 100.00 & 88.18 & 100.00 & 91.82 & 100.00 & 92.73 \\
\hline OA & \multicolumn{2}{|c|}{77.17} & \multicolumn{2}{|c|}{79.75} & \multicolumn{2}{|c|}{83.11} & \multicolumn{2}{|c|}{85.90} \\
\hline
\end{tabular}

Note: UA = user's accuracy; PA = producer's accuracy; OA = overall accuracy.

producer's accuracy (PA), user's accuracy (UA), and Kappa coefficient (Congalton et al., 1983; Congalton, 1991; Kalkhan et al., 1997; Smits et al., 1999). The Kappa coefficient is a measure of the overall agreement of a matrix that takes nondiagonal elements into account. Kappa analysis is recognized as a powerful technique used for analyzing a single error matrix and comparing the difference between different error matrices (Congalton, 1991; Smits et al., 1999). A detailed description of the Kappa analysis can be found in Congalton et al. (1983), Hudson and Ramm (1987), Congalton (1991), Kalkhan et al. (1997), and Smits et al. (1999). In this paper, an error matrix for each classification method was produced and UA, PA, and OA were calculated for each classification method. The KHAT statistic, Kappa variance, and Z statistic were used to compare the performance among different classification methods. A total of 320 sample plots, covering different land-cover types, were randomly allocated and examined using field data and an Ikonos image.

\section{Results and Discussion}

The seven land-cover classes-mature forest, SS2, SS1, pasture, agricultural lands, bare lands, and water-were classified using four different classifiers, and classification accuracy assessments were conducted (Table 1). The classification accuracies of forest, pasture, agricultural lands, and water were satisfactory, but the accuracy of secondary succession stages, especially SS2, was poor. The DTC-LSMA approach generally provided the highest accuracies for all classes. Considering the overall accuracy, DTC-LSMA provided the best classification results with 85.9 percent and MDC provided the poorest results with overall accuracy of 77.2 percent.

Tables 2 and 3 provide a comparison of kappa analysis results among the different classifiers. It indicates that DTC-LSMA has a significantly better KHAT than do MDC and MLC at a 90 percent confidence level. ECHO has a significantly better KHAT than does MDC at a 90 percent confidence level. MLC and MDC do not have a significant difference in the KHAT coefficients.

The classification results indicate that some classes are more difficult to differentiate than others. For example, ss2 was often confused with some SS1 sites and some coffee plantations in agricultural lands. SS1 was also confused with degraded pastures and some agricultural lands. Sparse and drier pasture sites were sometimes confused with bare lands. Also, the variances within these classes are different for distinct land-cover types. Mature forest has relatively smaller variance than succession stages, pasture, and agricultural lands. This characteristic makes mature forest easier to classify using any of the four classifiers. For those land covers, such as pasture, with relatively larger variance, MDC produced a lower classification accuracy because it only used the mean vector and ignored the covariance between the classes. MLC produced a relatively higher accuracy than did MDC because it takes the covariance into account in its algorithm. However, MLC assumes a normal distribution for the histograms of the classes, which is not always true. Both MDC and MLC only consider per-pixel information, ignoring texture or contextual information. Areas with complex landscapes such as the rural settlement studied in Rondônia benefit from the incorporation of texture information to improve the classification results. ECHO took advantage of spatial information to provide better classification results for selected classes within the study area.

Figure 3 illustrates the comparison of reflectance curves (Figure 3a) and fractions (Figure 3b) of selected land-cover types. Figure 3a shows the difficulty in differentiating between SS1, ss2, degraded pasture, cultivated pasture, and coffee plantation in agricultural lands based solely on spectral signatures. Fraction values (Figure 3b) developed using LSMA provided better separation between these classes. For example, secondary succession has very low soil fractions. The degraded pasture and coffee plantation have higher soil fractions than successional vegetation but lower than cultivated pasture. Secondary succession has higher GV fractions than cultivated or degraded pastures, while coffee plantation has the lowest GV fraction but the highest shade fraction compared to secondary succession and pastures. This indicates that fraction images can better separate these Amazonian land-cover types than do spectral signatures. The distinction between SS1 and SS2 is difficult because the majority of successional vegetation in the study area is less than 10 years old. The vegetation stand structure between these SS1 and SS2 sites cannot

TABle 2. COMPARISON OF KHAT AND VARIANCE AMONG CLASSIFICATION METHOdS

\begin{tabular}{lll}
\hline Classifier & KHAT & Variance \\
\hline MDC & 0.7162 & 0.000871 \\
MLC & 0.7560 & 0.000788 \\
ECHO & 0.7920 & 0.000745 \\
DTC-LSMA & 0.8160 & 0.000503 \\
\hline
\end{tabular}

TABLE 3. COMPARISON OF KAPPA ANALYSIS RESULtS BETWEEN CLASSIFICATION METHODS

\begin{tabular}{lcccc}
\hline Classifier & No. & Combination & Z_stat & Result \\
\hline MDC & 1 & (4) vs. (1) & 2.6912 & S (95\%) \\
MLC & 2 & (4) vs. (2) & 1.6693 & S (90\%) \\
ECHO & 3 & (4) vs. (3) & 0.6787 & NS \\
DTC-LSMA & 4 & (3) vs. (1) & 1.8850 & S (90\%) \\
& & (3) vs. (2) & 0.9196 & NS \\
& & (2) vs. (1) & 0.9762 & NS \\
\hline
\end{tabular}

Note: Z_stat $=$ Z statistic; $\mathrm{S}=$ significant; $\mathrm{NS}=$ not significant. 


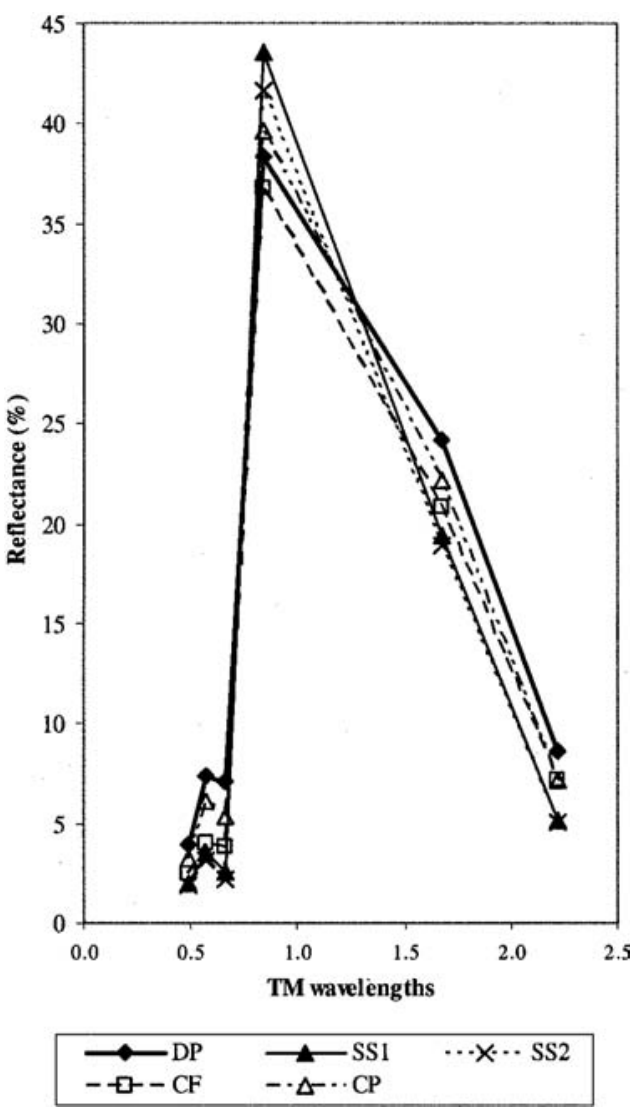

(a)

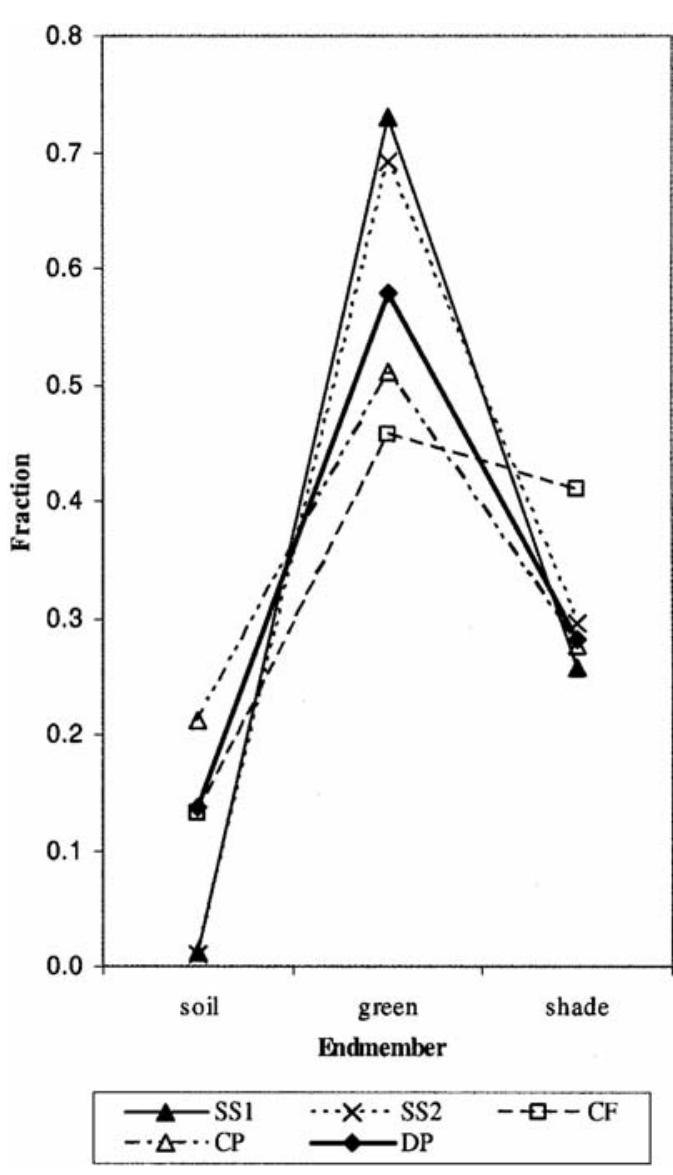

(b)

Figure 3. Comparison of TM reflectance (a) and fraction values (b) of selected land-cover types. Note: SS1 = initial secondary succession forest. SS2 = intermediate secondary succession forest. $\mathrm{CP}=$ cultivated pasture. $\mathrm{DP}=$ degraded pasture. $\mathrm{CF}=$ coffee plantation.

provide sufficient difference to distinguish them (Lu et al., 2003b). Thus, either per-pixel or sub-pixel classifiers cannot produce satisfactory classification results for such features in the newer colonization areas of Rondônia. This implies that grouping SS1 and SS2 into one class may be suitable for research addressing these areas in the Brazilian Amazon basin.

Landscape structure and land-cover dynamics are very complex in the moist tropical region of Amazonia (Batistella et al., 2003). Mixed pixels are common in TM data due to the heterogeneity of landscape and the limitation of $30-\mathrm{m}$ spatial resolution data. Because the classification problems associated with secondary succession stages are complex, traditional perpixel classifiers such as MLC and MDC are not recommended to be used to accurately classify these land covers based purely on TM spectral signatures. The MDC too broadly classified one succession class by often overlapping another succession class because the classifier lacks sophisticated spectral discrimination between very complex features. The MLC is more sophisticated, but being a per-pixel classifier, created a "salt and pepper" pattern classification, which showed, for example, that there were many pixels of SS2 mixed with SS1 and coffee plantation, and pixels of SS1 mixed with degraded pasture. MLC did not effectively identify areas of succession as indicated by ground-truth data.

To overcome some of these misclassifications, ECHO takes spectral and spatial information into account. Its algorithm effectively assigns scattered pixels to the dominant class in a given subregion based on criteria defined by the analyst. This removes most of the "salt and pepper" pattern by assigning only the most statistically divergent pixels to a class different from their neighborhood. Our results show that the use of texture and/or spatial/spectral relationships is essential in classifying complex successional environments in the Amazon. For different features such as a homogeneous crop or pasture, ECHO does little if anything to improve classification because the spectral heterogeneity does not exist. Another way to overcome misclassifications of mixed pixels is to use the spectral mixture analysis. The results obtained using DTC-LSMA more accurately discriminated between vegetation mosaics and gradients because its focus is on mixtures of feature elements. Hence, advanced classifiers, such as ECHO that incorporates spectral and spatial information and DTC-LSMA that uses sub-pixel information, improve classification results in complex Amazonia environments.

Although this research focuses on the moist tropical region of the western Brazilian Amazon basin, the conclusions are also valid for other study areas with complex landscape or vegetation stand structure. For example, the ECHO classifier has proven to provide good classification results in different sites of the eastern Amazon basin (Mausel et al., 1993; Brondizio et al., 1996). DTC-LSMA has produced good results in the Amazonian land-cover classification (Adams et al., 1995; Roberts et al., 1998a) and in urban land-cover classifications (Rashed et al., 2001; Phinn et al., 2002). 


\section{Conclusions}

Different classifiers have their own advantages and disadvantages. For a given research topic, deciding which classifier is more appropriate depends on a variety of factors. If robust training sample data and different classifiers are available, selecting a suitable classification approach is crucial to achieve good results. Even though some classifiers provide more accurate results than others, all four used in this research are useful in extracting land-cover information. However, of the four classifiers tested, DTC-LSMA and ECHO are the two most recommended approaches when classifying mature forest, different stages of secondary succession, pasture, agricultural lands, bare lands, and water. Sophisticated algorithms are needed to successfully discriminate distinct features in complex environments. In this case, classification problems will be either related to spatial/ spectral aspects or to spectral mixtures at a given resolution. Our results show that ECHO and DTC-LSMA had the best performance to address the land-cover heterogeneity of the study area.

It is interesting to note that the overall accuracies of the four classifiers used in this study increase from the least complex or most automated algorithms to the most complex or multistage classifiers. DTC-LSMA is conceptually the most complex algorithm and ECHO has four stages, three of which require analyst input. Assuming identical training sample data, analysts with extensive experience working with more complex classification approaches will often get better results, while analysts using less complex classifiers may get poorer results. Thus, consideration of an analyst's experience and understanding of a given classifier and of the complexity of a study area should be an important factor in selecting which algorithm to use in addition to which algorithms might theoretically be most powerful. The results presented in this paper contribute to identifying more suitable classifier to consider for land-cover monitoring in the Brazilian Amazon basin.

\section{Acknowledgments}

The authors wish to thank the National Science Foundation (grants 95-21918 and 99-06826), the National Aeronautics and Space Administration (grant N005-334), and Brazil's CAPES (Program for the Advancement of Education) for their support, which provided funds for the research that led to this paper. This project is part of the Large-Scale Biosphere-Atmosphere Experiment in Amazônia (LBA) program, LC-09, examining the human and physical dimensions of land-use and land-cover change. We also thank Indiana State University and Indiana University for facilities and support of our work and collaborators in Brazil, especially the LBA Program, EMBRAPA, INPE, and the population of the study area, who made this work possible. The authors wish to thank the journal reviewers for their constructive suggestions.

\section{References}

Adams, J.B., M.O. Smith, and A.R. Gillespie, 1993. Imaging spectroscopy: Interpretation based on spectral mixture analysis, $R e$ mote Geochemical Analysis, Topics in Remote Sensing 4 (C.M. Pieters and P.A.J. Englert, editors), Cambridge University Press, Cambridge, United Kingdom, pp. 145-166.

Adams, J.B., D.E. Sabol, V. Kapos, R.A. Filho, D.A. Roberts, M.O. Smith, and A.R. Gillespie, 1995. Classification of multispectral images based on fractions of endmembers: Application to landcover change in the Brazilian Amazon, Remote Sensing of Environment, 52:137-154.

Aguiar, A.P.D., Y.E. Shimabukuro, and N.D.A. Mascarenhas, 1999. Use of synthetic bands derived from mixing models in the multispectral classification of remote sensing images, International Journal of Remote Sensing, 20:647-657.

Alonso, G.F., and S.L. Soria, 1991. Using contextual information to improve land use classification of satellite images in central Spain, International Journal of Remote Sensing, 12:2227-2235.
Aplin, P., P.M. Atkinson, and P.J. Curran, 1999. Per-field classification of land use using the forthcoming very fine spatial resolution satellite sensors: Problems and potential solutions, Advances in Remote Sensing and GIS Analysis (P.M. Atkinson and N.J. Tate, editors), John Wiley \& Sons Ltd., New York, N.Y., pp. 219-239.

Arai, K., 1993. A classification method with a spatial-spectral variability, International Journal of Remote Sensing, 14:699-709.

Bateson, A., and B. Curtiss, 1996. A method for manual endmember selection and spectral unmixing, Remote Sensing of Environment, 55:229-243.

Batistella, M., 2001. Landscape Change and Land-Use/Land-Cover Dynamics in Rondônia, Brazilian Amazon, Ph.D. dissertation, Indiana University, Bloomington, Indiana, $399 \mathrm{p}$.

Batistella, M., S. Robeson, and E.F. Moran, 2003. Settlement design, forest fragmentation, and landscape change in Rondônia, Amazônia, Photogrammetric Engineering \& Remote Sensing, 69:805-812.

Biehl, L., and D. Landgrebe, 2002. MultiSpec-A tool for multispectral-hyperspectral image data analysis, Computers $\&$ Geosciences, 28:1153-1159.

Boardman, J.M., F.A. Kruse, and R.O. Green, 1995. Mapping target signature via partial unmixing of AVIRIS data, Summaries of the Fifth JPL Airborne Earth Science Workshop, 23-26 January, Pasadena, California (JPL Publication 95-1, NASA Jet Propulsion Laboratory, Pasadena, California), pp. 23-26.

Bognola, I.A., and A.F. Soares, 1999. Solos das "glebas 01, 02,03 e 06 " do Município de Machadinho d'Oeste, $R O$, Pesquisa em Andamento, n.10. EMBRAPA Monitoramento por Satélite, Campinas, Brazil, 7 p.

Brondízio, E., E. Moran, P. Mausel, and Y. Wu, 1996. Land cover in the Amazon estuary: Linking of TM with botanical and historical data, Photogrammetric Engineering \& Remote Sensing, 62:921-930.

Chavez, P.S., Jr., 1996. Image-based atmospheric corrections—Revisited and improved, Photogrammetric Engineering \& Remote Sensing, 62:1025-1036.

CIPEC, 1998. International Forestry Resources and Institutions (IFRI) Research Program, Field Manual, Center for the Study of Institutions, Population, and Environmental Change (CIPEC), Indiana University, Bloomington, Indiana, 273 p.

Cochrane, M.A., and C.M. Souza, Jr., 1998. Linear mixture model classification of burned forests in the eastern Amazon, International Journal of Remote Sensing, 19:3433-3440.

Congalton, R.G., 1991. A review of assessing the accuracy of classification of remotely sensed data, Remote Sensing of Environment, 37:35-46.

Congalton, R.G., R.G. Oderwald, and R.A. Mead, 1983. Assessing Landsat classification accuracy using discrete multivariate analysis statistical techniques, Photogrammetric Engineering \& Remote Sensing, 49:1671-1678.

Foody, G.M., 1996. Approaches for the production and evaluation of fuzzy land cover classification from remotely-sensed data, International Journal of Remote Sensing, 17:1317-1340.

Foody, G.M., M.B. McCulloch, and W.B. Yates, 1995. Classification of remotely sensed data by an artificial neural network: issues related to training data characteristics, Photogrammetric Engineering \& Remote Sensing, 61:391-401.

Friedl, M.A., and C.E. Brodley, 1997. Decision tree classification of land cover from remotely sensed data, Remote Sensing of Environment, 61:399-409,

Garcia-Haro, F.J., M.A. Gilabert, and J. Melia, 1996. Linear spectral mixture modeling to estimate vegetation amount from optical spectral data, International Journal of Remote Sensing, 17:3373-3400.

Hudson, W.D., and C.W. Ramm, 1987. Correct formulation of the Kappa coefficient of agreement, Photogrammetric Engineering \& Remote Sensing, 53:421-422.

Huguenin, R.L., M.A. Karaska, D.V. Blaricom, and J.R. Jensen, 1997. Subpixel classification of Bald Cypress and Tupelo Gum trees in Thematic Mapper imagery, Photogrammetric Engineering \& Remote Sensing, 63:717-725.

INPE, 2002. Monitoring of the Brazilian Amazon Forest by Satellite 2000-2001, Instituto Nacional de Pesquisas Espaciais (INPE), São Paulo, Brazil, 21 p. 
Jensen, J.R., 1996. Introductory Digital Image Processing: A Remote Sensing Perspective, Second Edition, Prentice Hall, Upper Saddle River, New Jersey, 379 p.

Kalkhan, M.A., R.M. Reich, and R.L. Czaplewski, 1997. Variance estimates and confidence intervals for the Kappa measure of classification accuracy, Canadian Journal of Remote Sensing, 23:210-216.

Kartikeyan, B., B. Gopalakrishna, M.H. Kalubarme, and K.L. Majumder, 1994. Contextual techniques for classification of high and low resolution remote sensing data, International Journal of Remote Sensing, 15:1037-1051.

Kettig, R.L., and D.A. Landgrebe, 1976. Computer classification of remotely sensed multispectral image data by extraction and classification of homogeneous objects, IEEE Transactions on Geoscience Electronics, GE-14:19-26.

Landgrebe, D.A., 1980. The development of a spectral-spatial classifier for Earth observational data, Pattern Recognition, 12:165-175.

Li, Y, E.F. Moran, E.S. Brondízio, P. Mausel, and Y. Wu, 1994. Discrimination between advanced secondary succession and mature moist forest near Altamira, Brazil using Landsat TM data, Proceedings of the ASPRS 1994 Annual Meeting, 23-28 May, Reno, Nevada (American Society for Photogrammetry and Remote Sensing and American Congress on Surveying and Mapping, Bethesda, Maryland), 1:350-364.

Lillesand, T.M., and R.W. Kiefer, 2000. Remote Sensing and Image Interpretation, Fourth Edition, John Wiley \& Sons, New York, N.Y., 724 p.

Lu, D., 2001. Estimation of Forest Stand Parameters and Application in Classification and Change Detection of Forest Cover Types in the Brazilian Amazon Basin, Ph.D. dissertation, Indiana State University, Terre Haute, Indiana, 235 p.

Lu, D., P. Mausel, E. Brondízio, and E. Moran, 2002. Assessment of atmospheric correction methods for Landsat TM data applicable to Amazon basin LBA research, International Journal of Remote Sensing, 23:2651-2671.

Lu, D., M. Batistella, and E. Moran, 2003a. Integration of vegetation inventory data and Thematic Mapper image for Amazonian successional and mature forest classification, Proceedings of the ASPRS 2003 Annual Conference, 05-09 May, Anchorage, Alaska (American Society for Photogrammetry and Remote Sensing, Bethesda, Maryland), unpaginated CD-ROM.

Lu, D., E. Moran, and M. Batistella, 2003b. Linear mixture model applied to Amazônian vegetation classification, Remote Sensing of Environment, 87(4):456-469.

Lucas, R.M., M. Honzák, G.M. Foody, P.J. Curran, and C. Corves, 1993. Characterizing tropical secondary forests using multitemporal Landsat sensor imagery, International Journal of Remote Sensing, 14:3061-3067.

Lucas, R.M., M. Honzak, S. do Amaral, P.J. Curran, and G.M. Foody, 2002. Forest regeneration on abandoned clearance in central Amazonia, International Journal of Remote Sensing, 23:965-988.

Mannan, B., J. Roy, and A.K. Ray, 1998. Fuzzy ARTMAP supervised classification of multi-spectral remotely-sensed images, International Journal of Remote Sensing, 19:767-774.

Mather, P.M., 1999. Computer Processing of Remotely-Sensed Images: An Introduction, Second Edition, John Wiley \& Sons, New York, N.Y., 306 p.

Mausel, P., Y. Wu, Y. Li, E. Moran, and E. Brondízio, 1993. Spectral identification of succession stages following deforestation in Amazonia, Geocarto International, 8:11-20.

Moran, E.F., 1981. Developing the Amazon, Indiana University Press, Bloomington, Indiana, $292 \mathrm{p}$.

Moran, E.F., E.S. Brondízio, and P. Mausel, 1994. Secondary succession, Research and Exploration, 10:458-476.

Mustard, J.F., and J.M. Sunshine, 1999. Spectral analysis for earth science: investigations using remote sensing data, Remote Sensing for the Earth Sciences: Manual of Remote Sensing, Third Edition, Volume 3 (A.N. Rencz, editor), John Wiley \& Sons, New York, N.Y., pp. 251-307.

Paola, J.D., and R.A. Schowengerdt, 1997. The effect of neural-network structure on a multispectral land-use/land-cover classification, Photogrammetric Engineering \& Remote Sensing, 63:535-544.

Pedley, M.I., and P.J. Curran, 1991. Per-field classification: An example using SPOT HRV imagery, International Journal of Remote Sensing, 12:2181-2192.
Phinn, S., M. Stanford, P. Scarth, A.T. Murray, and P.T. Shyy, 2002. Monitoring the composition of urban environments based on the vegetation-impervious surface-soil (VIS) model by subpixel analysis techniques, International Journal of Remote Sensing, 23:4131-4153.

Rashed, T., J.R. Weeks, M.S. Gadalla, and A.G. Hill, 2001. Revealing the anatomy of cities through spectral mixture analysis of multisepctral satellite imagery: A case study of the Greater Cairo region, Egypt, Geocarto International, 16:5-15.

Richards, J.A., and X. Jia, 1999. Remote Sensing Digital Image Analysis: An Introduction, Third Edition, Springer-Verlag, Berlin, Germany, $363 \mathrm{p}$.

Rignot, E., W.A. Salas, and D.L. Skole, 1997. Mapping deforestation and secondary growth in Rondônia, Brazil, using imaging radar and Thematic Mapper data, Remote Sensing of Environment, 59:167-179.

Roberts, D.A., G.T. Batista, J.L.G. Pereira, E.K. Waller, and B.W. Nelson, 1998a. Change identification using multitemporal spectral mixture analysis: Applications in eastern Amazônia, Remote Sensing Change Detection: Environmental Monitoring Methods and Applications (R.S. Lunetta and C.D. Elvidge, editors), Ann Arbor Press, Ann Arbor, Michigan, pp. 137-161.

Roberts, D.A., M. Gardner, R. Church, S. Ustin, G. Scheer, and R.O. Green, 1998b. Mapping chaparral in the Santa Monica mountains using multiple endmember spectral mixture models, Remote Sensing of Environment, 65:267-279.

Rogan, J., J. Franklin, and D.A. Roberts, 2002. A comparison of methods for monitoring multitemporal vegetation change using Thematic Mapper imagery, Remote Sensing of Environment, 80: 143-156.

Rondônia, 1998. Diagnóstico sócio-econômico do Estado de Rondônia e assistência técnica para formulação da segunda aproximação do zoneamento sócio-econômico-ecológico-Climatologia, v. 1. Governo de Rondônia/PLANAFLORO, Porto Velho, Brazil, 401 p.

Schmink, M., and C.H. Wood, 1992. Contested Frontiers in Amazônia, Columbia University Press, New York, N.Y., 387 p.

Settle, J.J., and N.A. Drake, 1993. Linear mixing and the estimation of ground cover proportions, International Journal of Remote Sensing, 14:1159-1177.

Shimabukuro, Y.E., and J.A. Smith, 1991. The least-squares mixing models to generate fraction images derived from remote sensing multispectral data, IEEE Transactions on Geoscience and Remote Sensing, 29:16-20.

1995. Fraction images derived from Landsat TM and MSS data for monitoring reforested areas, Canadian Journal of Remote Sensing, 21:67-74.

Small, C., 2001. Estimation of urban vegetation abundance by spectral mixture analysis, International Journal of Remote Sensing, 22:1305-1334.

Smith, M.O., S.L. Ustin, J.B. Adams, and A.R. Gillespie, 1990. Vegetation in Deserts: I. A regional measure of abundance from multispectral images, Remote Sensing of Environment, 31:1-26.

Smits, P.C., S.G. Dellepiane, and R.A. Schowengerdt, 1999. Quality assessment of image classification algorithms for land-cover mapping: A review and a proposal for a cost-based approach, International Journal of Remote Sensing, 20:1461-1486.

Theseira, M.A., G. Thomas, and C.A.D. Sannier, 2002. An evaluation of spectral mixture modeling applied to a semi-arid environment, International Journal of Remote Sensing, 23:687-700.

Tompkins, S., J.F. Mustard, C.M. Pieters, and D.W. Forsyth, 1997. Optimization of endmembers for spectral mixture analysis, Remote Sensing of Environment, 59:472-489.

Ustin, S.L., Q.J. Hart, L. Duan, and G. Scheer, 1996. Vegetation mapping on hardwood rangelands in California, International Journal of Remote Sensing, 17:3015-3036.

van der Meer, F., and S.M. de Jong, 2000. Improving the results of spectral unmixing of Landsat Thematic Mapper imagery by enhancing the orthogonality of end-members, International Journal of Remote Sensing, 21:2781-2797.

(Received 21 October 2002; accepted 19 May 2003; revised 10 June 2003) 